\title{
Sensitization to profilin in the Central region of Portugal
}

\author{
Beatriz Tavares ${ }^{a, b, *}$, Daniel Machado ${ }^{a}$, Graça Loureiro ${ }^{a}$, \\ Jessica Cemlyn-Jones ${ }^{a}$, Celso Pereira ${ }^{a, c}$ \\ a Immunoallergology Department, Coimbra University Hospitals, Apartado 9057, 3001-301 Coimbra, Portugal \\ bImmunoallergology Center, Rua Padre António Vieira, 8 c/v, 3000-315 Coimbra, Portugal \\ 'Immunoallergology Department, Centro Diagnóstico, Rua Pedro Álvares Cabral, 6200 Covilhã, Portugal
}

\section{A R T I C L E D A T A}

Article history:

Received 2 June 2008

Received in revised form 30 July 2008

Accepted 7 August 2008

Available online 11 September 2008

Keywords:

Oral allergy syndrome

Pollen

Pollen-food cross-reactivity

Profilin

Sensitization

\begin{abstract}
A B S T R A C T
Background: Profilin is a panallergen found in pollens and fruits. Sensitization to this protein may explain some sensitization to multiple pollen species. We aimed to evaluate sensitization to profilin in patients suffering from respiratory allergy sensitized to pollens, in the Central region of Portugal.

Methods: Patients were evaluated for asthma symptoms, rhinitis, conjunctivitis and food allergy. Skin prick tests (SPT) to aeroallergens including 12 different pollens and profilin (nPho d 2) were performed. The patients were divided into two study groups according to the region of residence: $\mathrm{A}$ - inland region and $\mathrm{B}$ - coastal region.

Results: A total of 370 patients were evaluated (277-group A; 93-group B). 65.9\% showed positive skin prick tests and $76.2 \%$ were positive to pollens (87.1\%-group A; $42.85 \%$-group $B ; p<0.0001)$. All the patients sensitized to pollens had rhinitis $(p=0.001)$. Sensitization to profilin was associated with pollen sensitization $(p=0.014) .43$ patients were sensitized to profilin (40-group A; 3-group B; $p=0.006$ ). $21.0 \%$ of patients sensitized to pollens, were also sensitized to profilin. 39 patients were sensitized to at least two pollens $(p<0.0001)$. Four profilin and pollen sensitized patients had oral allergy syndrome complaints to melon. This syndrome was related with profilin sensitization $(p=0.001)$.

Conclusions: It is advisable to perform SPT to profilin, particularly in the Inland region, for a better differential diagnosis between cross-reactivity and true sensitization to pollens. The results together with the medical history may support the choice for a specific immunotherapy option.
\end{abstract}

() 2008 Elsevier B.V. All rights reserved.

\section{Introduction}

The high allergen exposure namely to pollens, is one of the pointed factors that has been linked with the increase in prevalence of allergic diseases such as asthma, and rhinoconjunctivitis (Jarvis and Burney, 1998; Taylor et al., 2007; Gilmour et al., 2006). Climate changes result in an increase of the allergen burden, a fact that combined with pollutant exposures, can act synergistically to enhance the allergic response, and increase respiratory symptoms (Gilmour et al., 2006; D'Amato et al., 2007a,b; Beggs, 2004). The patterns of sensitization to pollens depend on exposure and differ according to region, since the climate, geography, and vegetation diverge (D'Amato et al., 2007a,b).

A study of aeroallergen sensitization in different regions of Portugal evaluated by skin prick tests (SPT), showed a higher level of sensitization to pollens, particularly to grasses and Parietaria, in the Central region compared with the other

\footnotetext{
* Corresponding author. Serviço de Imunoalergologia, Hospitais da Universidade de Coimbra, Apartado 9057, $3001-301$ Coimbra, Portugal. Tel.: +351 917276932; fax: +351 309902002.

E-mail addresses: beatriztavares@net.sapo.pt, tavares.beatriz@gmail.com (B. Tavares).
} 
regions (Pereira et al., 2006). Pollen sensitization assumes particular relevance in the Inland Central region of the country (Loureiro et al., 2005).

Several studies report a high prevalence of sensitization to different pollen species belonging to taxonomically distant families (Valenta et al., 1992; Mari, 2001). This can be explained by sensitization to panallergens present in pollens, namely profilins and calcium-binding proteins (Valenta et al., 1991, 1992, 1998; Radauer et al., 2006; Ebner et al., 1995).

Profilins are small actin-binding proteins of $12-15 \mathrm{kDa}$ in size (Thorn et al., 1997; Witke, 2004). They have been well preserved during evolution, namely the protein folds, and can be found in all eukaryotic cells. They are essential in all organisms since they regulate the dynamics of actin polymerization, for in vivo motility, and function as hubs that control a complex network of molecular interactions (Witke, 2004). The plant derived class of profilins show a high sequence homology (50 to $80 \%$ ) (Radauer et al., 2006; Thorn et al., 1997). Profilin was first reported as a minor allergen in birch pollen (Valenta et al., 1991).

Profilins from pollen and plant foods, are highly crossreactive and elicit IgE responses in 10-30\% of pollen-allergic patients (Valenta et al., 1992; Asero et al., 2008). They may be responsible for several pollen-food allergy syndromes (Egger et al., 2006). The identification and purification of such a panallergen for diagnostic purposes, allowed the understanding of several clinical observations with consequential therapeutic implications.

The aim of this study was to evaluate sensitization to profilin in patients suffering from respiratory allergy, sensitized to pollens, in the Central region of Portugal (Inland and Coastal regions).

2.

\section{Methods}

\subsection{Patients}

The study was carried out in five Allergy Medical Centres located in the Central region of Portugal, in the cities of Covilhã and Oliveira do Hospital (Inland region); Leiria, Fátima and Entroncamento (Coastal region) (Fig. 1).

The study was performed with the consent of the patients or their representatives.

We assessed all consecutive patients observed for the first time for allergic respiratory symptoms, during a three-month period (from the beginning of February to the end of April). They were evaluated for asthma symptoms, rhinitis, conjunctivitis and food allergy including oral allergy syndrome (Ortolani et al., 1988), by means of medical history. Skin prick tests were carried out in all the patients that met inclusion criteria.

Exceptions included pregnant women, patients that were previously submitted to specific immunotherapy and patients that had some contra-indication for the performance of skin prick tests.

\subsection{Skin prick tests}

The patients studied were submitted to skin prick tests (SPT) with commercial standardized extracts of aeroallergens, with

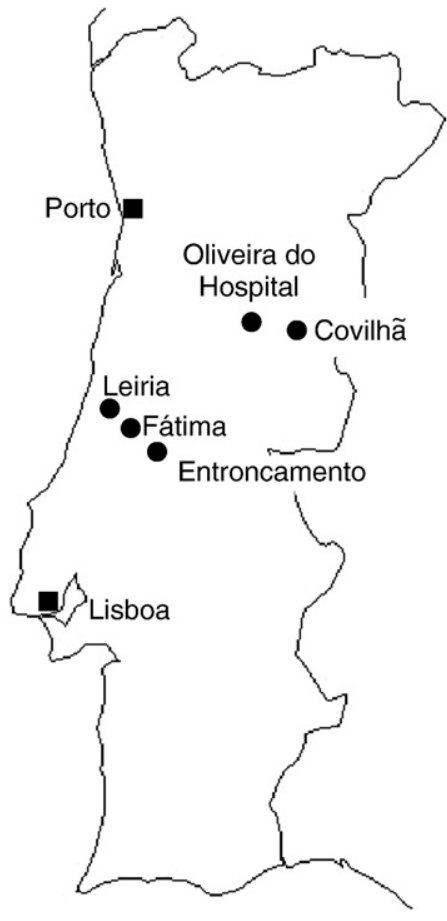

Fig. 1-Location of the Centres where the study was performed.

known potency, including house dust mites, cat and dog dander, moulds, twelve different pollen species representative of the corresponding botanical family, and reflecting the most important range of known allergenicity and exposure levels of the regions, and profilin from Phoenix dactilyfera (date palm) pollen (Pho d 2, $50 \mu \mathrm{g} / \mathrm{ml}$ ) (ALKAbelló, Madrid, Spain). We used for skin testing in all the study centres the same extracts, including the pollen extracts. Histamine hydrochloride (10 $\mathrm{mg} / \mathrm{ml})$ and saline were used as positive and negative controls respectively. The tests were performed and interpreted according to the European Academy of Allergology and Clinical Immunology recommendations (Dreborg, 1989). Lancets with $1 \mathrm{~mm}$ were used for skin pricking (ALKAbelló, Madrid, Spain). The mean of the longest and the midpoint orthogonal diameters (mean diameter) of wheal size were considered for analysis, and a wheal diameter $\geq 3 \mathrm{~mm}$ greater than that induced by the negative control was regarded as positive.

The tests were performed by one investigator in the Covilhã Centre and by another researcher in all the other Centres.

\subsection{Statistical analysis}

Statistical analysis was performed with SPSS 15.0 (2006 SPSS Inc, Chicago, Ill, USA). Frequency distribution was obtained for the different qualitative variables. Average and Standard Deviation (SD) were calculated, for quantitative variables. Patients were divided into two study groups according to the region of residence: group A - inland region; and group B coastal region. Sub-groups were defined according to positive results in SPT and at least one pollen sensitization. Differences between the two groups were analysed by means of $\chi^{2}$ tests 


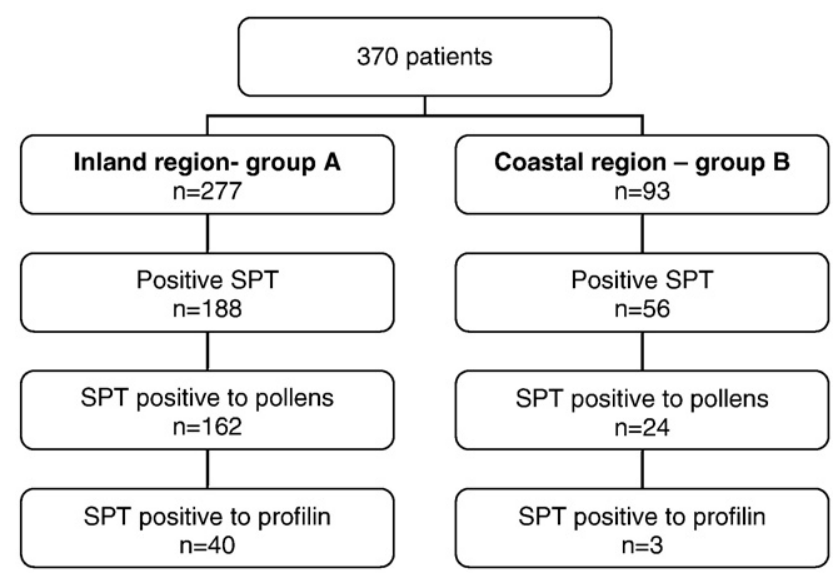

Fig. 2-Organogram of distribution of patients by groups $\mathbf{A}$ and $B$.

and Mann-Whitney test (two independent samples) for qualitative and quantitative variables respectively. Sensitization to profilin and pollens was evaluated by $\chi^{2}$ tests. We considered three groups of patients sensitized to pollens for analysis: those with sensitization to more than one pollen, those sensitized to at least six pollens and those monosensitized to grasses. Significance was considered for a $p$ value less than 0.05 .

\section{Results}

\subsection{Overall analysis}

A total of 370 patients were evaluated, 277 in group A and 93 in group B. The average age was $27.08 \pm 17.49$ years old (group A $25.27 \pm 16.68$ and group B $32.46 \pm 18.80 ; p=0.0001$ ). $62.2 \%$ were female (group A $59.2 \%$ and group B $71.0 \% ; p=0.004$ ).

The distribution of asthma, rhinitis and conjunctivitis was $53.4 / 47.3,53.8 / 90.3$ and $8.7 / 20.4 \%$ in groups $A$ versus $B$ respectively.

\section{Table 1 - Demographic and clinical data}

\begin{tabular}{|c|c|c|c|c|}
\hline & \multicolumn{4}{|c|}{ Pollen positive SPT } \\
\hline & $\begin{array}{l}\text { Total } \\
n / \%\end{array}$ & $\underset{n / \%}{\text { Group } A}$ & $\underset{n / \%}{\text { Group }}$ B & $p$ \\
\hline$n$ & $186 / 76.2$ & $162 / 87.1$ & $24 / 12.9$ & $<0.0001$ \\
\hline Gender & 79/107 & 71/91 & $8 / 16$ & 0.332 \\
\hline (male/female) & $42.5 / 57.5 \%$ & $43.8 / 56.2 \%$ & $33.3 / 66.7 \%$ & \\
\hline Age yrs & $\begin{array}{l}23.93 \pm \\
13.97\end{array}$ & $\begin{array}{l}23.51 \pm \\
13.99\end{array}$ & $\begin{array}{l}26.79 \pm \\
13.77\end{array}$ & 0.220 \\
\hline Asthma (total) & $101 / 54.3$ & $90 / 55.6$ & $11 / 45.8$ & 0.372 \\
\hline Rhinitis (total) & $134 / 72.0$ & $110 / 67.9$ & $24 / 100.0$ & 0.001 \\
\hline Conjunctivitis (total) & 28/15.1 & $22 / 13.6$ & $6 / 25.0$ & 0.144 \\
\hline Rhino-conjunctivitis & $23 / 12.4$ & $20 / 12.3$ & $3 / 12.5$ & 0.598 \\
\hline Asthma and rhinitis & $68 / 36.6$ & $60 / 37.0$ & $8 / 33.3$ & 0.725 \\
\hline $\begin{array}{l}\text { Asthma and rhino- } \\
\text { conjunctivitis }\end{array}$ & $4 / 2.2$ & $1 / 0.6$ & $3 / 12.5$ & 0.007 \\
\hline Food allergy (OAS) & $4 / 2.2$ & $3 / 1.9$ & $1 / 4.2$ & 0.466 \\
\hline
\end{tabular}

\section{Table 2 - Sensitization to pollens and profilin}

\begin{tabular}{lllll} 
& \multicolumn{4}{c}{ Pollen positive SPT } \\
\cline { 2 - 5 } & $\begin{array}{c}\text { Total } \\
n / \%\end{array}$ & $\begin{array}{c}\text { Group A } \\
n / \%\end{array}$ & $\begin{array}{c}\text { Group B } \\
n / \%\end{array}$ & $p$ \\
\hline Patients & $186 / 76.2$ & $162 / 87.1$ & $24 / 12.9$ & $<0.0001$ \\
Profilin & $39 / 21.0$ & $36 / 22.2$ & $3 / 12.5$ & 0.275 \\
Platanus acerifolia & $60 / 32.3$ & $57 / 35.2$ & $3 / 12.5$ & 0.027 \\
Betula verrucosa & $58 / 31.7$ & $57 / 35.2$ & $1 / 4.8$ & 0.005 \\
Olea europaea & $88 / 47.3$ & $81 / 50.0$ & $7 / 29.2$ & 0.056 \\
Quercus robur & $43 / 23.5$ & $39 / 24.2$ & $4 / 18.2$ & 0.531 \\
Robinia pseudoacacia & $56 / 31.1$ & $53 / 33.3$ & $3 / 14.3$ & 0.076 \\
Tilia cordata & $49 / 27.1$ & $47 / 29.6$ & $2 / 9.1$ & 0.043 \\
Pinus sylvestris & $53 / 29.4$ & $53 / 33.3$ & $0 / 0.0$ & 0.002 \\
Grasses* & $134 / 72.0$ & $113 / 69.8$ & $21 / 87.5$ & 0.071 \\
Parietaria judaica & $80 / 43.0$ & $68 / 42.0$ & $12 / 50.0$ & 0.459 \\
Artemisia vulgaris & $73 / 39.2$ & $65 / 40.1$ & $8 / 33.3$ & 0.525 \\
Plantago lanceolata & $107 / 57.5$ & $94 / 58.0$ & $13 / 54.2$ & 0.721 \\
Chenopodium album & $73 / 39.2$ & $60 / 37.0$ & $13 / 54.2$ & 0.109 \\
\hline "Crasses mixture in & & &
\end{tabular}

*Grasses mixture included: Dactylis glomerata, Festuca pratensis,

Lolium perenne, Phleum pratense and Poa pratensis extracts.

A total of 244 (65.9\%) patients showed positive skin prick tests (188/277-67.9\% in group A and 56/93-60.2\% in group B) in which 186 (76.2\%) were positive to pollens (162/186-87.1\% in group A and $24 / 56-42.85 \%$ in group B). The prevalence of sensitization to profilin was $11.62 \%$. Fig. 2, shows the distribution organogram of patients according to the several groups.

\subsection{Patients sensitized to pollens}

Demographic and clinical data of the patients sensitized to pollens are shown in Table 1. Patients from group A were more frequently sensitized to pollens than that from group $B$ $(p<0.0001)$.

Analysis of pollen positive SPT, showed that all the group B patients that had positive SPT to pollens suffered from rhinitis $(p=0.001)$. We could not observe any difference regarding asthma and conjunctivitis distribution, nor combined diagnosis

Table 3-SPT wheal diameters of patients with pollen positive SPT (average \pm SD)

\begin{tabular}{lcccc} 
& \multicolumn{4}{c}{ Pollen positive SPT } \\
\cline { 2 - 5 } & Total & Group A & Group B & $p$ \\
\hline Histamine & $5.73 \pm 2.19$ & $5.96 \pm 2.22$ & $4.13 \pm 0.90$ & $<0.0001$ \\
Platanus acerifolia & $4.15 \pm 1.78$ & $4.18 \pm 1.82$ & $3.67 \pm 0.57$ & 0.898 \\
Betula verrucosa & $4.33 \pm 2.26$ & $4.33 \pm 2.28$ & 4.0 & 0.793 \\
Olea europaea & $5.01 \pm 2.36$ & $4.93 \pm 2.29$ & $6.00 \pm 3.05$ & 0.342 \\
Quercus robur & $4.05 \pm 2.17$ & $4.08 \pm 2.24$ & $3.75 \pm 1.50$ & 0.825 \\
Robinia pseudoacacia & $3.55 \pm 1.27$ & $3.51 \pm 1.05$ & $4.33 \pm 2.31$ & 0.731 \\
Tilia cordata & $3.88 \pm 1.34$ & $3.87 \pm 1.36$ & $4.00 \pm 1.41$ & 0.823 \\
Pinus sylvestris & $3.79 \pm 1.50$ & $3.79 \pm 1.50$ & - & - \\
Grasses & $6.57 \pm 3.26$ & $6.66 \pm 3.47$ & $6.10 \pm 1.81$ & 0.983 \\
Parietaria judaica & $5.30 \pm 2.84$ & $5.49 \pm 3.01$ & $4.25 \pm 1.14$ & 0.538 \\
Artemisia vulgaris & $4.07 \pm 1.64$ & $4.02 \pm 1.59$ & $4.50 \pm 2.07$ & 0.429 \\
Plantago lanceolata & $5.19 \pm 3.26$ & $5.35 \pm 3.44$ & $4.00 \pm 0.82$ & 0.627 \\
Chenopodium album & $4.32 \pm 2.24$ & $4.45 \pm 2.43$ & $3.69 \pm 0.86$ & 0.652 \\
Profilin & $4.23 \pm 1.57$ & $4.15 \pm 1.51$ & $5.33 \pm 2.30$ & 0.218 \\
\hline
\end{tabular}


Table 4-Sensitization to profilin in patients with pollen positive SPT

\begin{tabular}{lcc} 
& \multicolumn{2}{c}{ Profilin positive SPT } \\
\cline { 2 - 3 } & Total $n / \%$ & $p$ \\
\hline Platanus acerifolia & $25 / 64.1$ & $<0.0001$ \\
Betula verrucosa & $22 / 56.4$ & $<0.0001$ \\
Olea europaea & $30 / 76.9$ & $<0.0001$ \\
Quercus robur & $21 / 53.8$ & $<0.0001$ \\
Robinia pseudoacacia & $23 / 59.0$ & $<0.0001$ \\
Tilia cordata & $22 / 56.4$ & $<0.0001$ \\
Pinus sylvestris & $15 / 38.5$ & 0.163 \\
grasses & $37 / 94.9$ & $<0.0001$ \\
Parietaria judaica & $25 / 64.1$ & 0.003 \\
Artemisia vulgaris & $29 / 74.4$ & $<0.0001$ \\
Plantago lanceolata & $29 / 74.4$ & 0.017 \\
Chenopodium album & $24 / 61.5$ & 0.001 \\
\hline
\end{tabular}

of rhino-conjunctivitis or asthma and rhinitis. The significant differences were only for those with asthma and rhinoconjunctivitis.

Four patients had oral allergy syndrome (OAS) complaints, related with the ingestion of melon and one patient also with the ingestion of apple, peach and plum.

Analysis of pollen positive SPT, showed that sensitization was significantly higher in group A to Platanus acerifolia, B. verrucosa, Tilia cordata and Pinus sylvestris. There were no significant differences between the two regions for the other pollens and profilin.

Table 2 shows the distribution of positive SPT to the different pollens and profilin.

For each pollen extract tested skin reactivity was similar in both groups.

Compared to the other pollens, the largest SPT average wheal diameter was to grasses pollen extract. Table 3 shows the SPT average wheal diameters to histamine, to the different pollens and profilin. Table 4 shows sensitization to profilin in patients with pollen positive SPT.

Forty three patients were sensitized to profilin. In the group of patients sensitized to pollens, 36 patients were observed in group A and only 3 in group B. Four patients (from group A) were not sensitized to any tested pollen extract. Two patients with perennial rhinitis were sensitized to mites and mites and dog respectively, and the other two patients (one with rhinitis and the other with asthma) were SPT negative for the other allergenic extracts.

$38.7 \%$ of patients were sensitized to at least half of the pollens tested and $78.5 \%$ were sensitized to at least two pollens. $7.5 \%$ of patients were mono-sensitized to grasses whereas $65.1 \%$ were sensitized to grasses and other pollens.

All the 39 patients sensitized to profilin and pollens, were sensitized to at least two pollens $(p<0.0001)$ (one of them was always grasses; $p=0.012$ ), and 31 of them were sensitized to at least half of the pollens tested $(p<0.0001)$ (Fig. 3).

Profilin sensitization was associated to male gender $(p=0.034)$ and oral allergy syndrome $(p=0.001)$. Association with asthma diagnosis, rhinitis or conjunctivitis was not found.

\section{Discussion}

This study was performed in two different regions of the Central region of Portugal. The Inland region has a mountainous topography, with a peak $2 \mathrm{~km}$ above the sea level. It has a continental climate, with cold winters and hot summers. The flora found in these zones varies from base to top of the mountains. The forest is frequent at lower altitudes and vegetation rich in weeds, grasses and shrubs is more frequent at the top. These conditions lead to high pollen counts in spring. The Coastal region is plain by the sea and rocky when one goes inland. It has a temperate climate with Atlantic influence. The soils are fertile for agriculture so, cultivated areas alternate with woodlands and forests. The pollen season is not as intense as in the Inland region (Instituto de Meteorologia. Portugal, 2008; SPAIC/Schering-Plough/CIPA, 1999).

In this study, we aimed to evaluate the sensitization to profilin in two groups of patients suffering from respiratory allergy, one from the Inland region and the other from the Coastal region, and the relationship with pollen sensitization and food allergy. This was the first study that assessed sensitization to profilin in Portugal.

All the patients had symptoms of asthma and/or rhinitis and/or conjunctivitis and were enquired for food allergy complaints, namely oral allergy syndrome (Ortolani et al., 1988).

Skin prick tests were carried out with a series of aeroallergens representative of the regions. Additionally, patients were

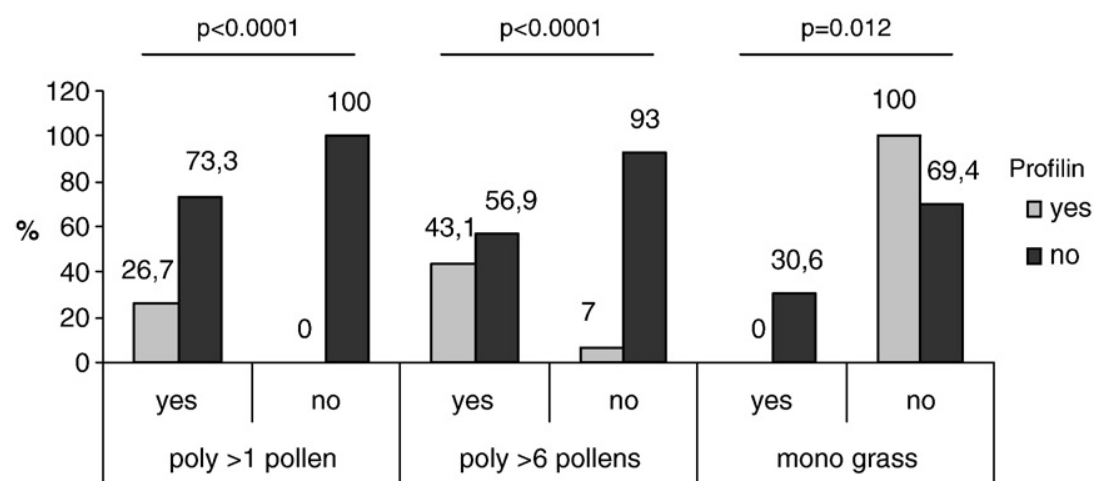

Fig. 3-Sensitization to pollens and profilin. Poly $>1$ pollen - sensitization to more than one pollen; poly $>6$ pollens - sensitization to at least 6 pollens; mono grasses - mono-sensitization to grasses. 
tested with profilin from Phoenix dactilyfera (date palm) pollen (Pho d 2). Pho d 2 is an important allergen as it is responsible for more than $70 \%$ of the IgE reactivity to the pollen extract. It has high sequence identity with other allergenic food and pollen profilins (Asturias et al., 2005; Kwaasi et al., 2002).

The large extent of cross-reactivity among plant profilins justifies using a single profilin for diagnosis. However, the fine specificity of IgE directed to variable epitopes may influence the clinical manifestation of profilin sensitization (Radauer et al., 2006). Natural profilin seems to be better for diagnosis than its recombinant counterpart both in vitro and in vivo, possibly because of improper folding of the recombinant molecule, as shown for rBet v 2 and nBet v 2 (van Ree et al., 1999; Pauli et al., 1996; Elfman et al., 1997; Wensing et al., 2002).

Performing SPT allowed the reactivity to carbohydrate determinants to be excluded, antigenic structures that have poor functional activity, but are responsible for a wide pattern of in vitro cross-reactivity among molecules with unrelated protein sequence (Mari, 2001; Aalberse and van Ree, 1997; Mari et al., 1999; van der Veen et al., 1997). Additionally, SPT have shown a high sensitivity but a low specificity for allergy diagnosis of asthma and rhinitis (Dreborg, 1989; Brand et al., 1993; Witteman et al., 1996; Bousquet et al., 2008).

Since the tests were performed by only two investigators, the variability upon investigator was reduced providing reliability to the tests results (Dreborg, 1989).

A total of $65.9 \%$ of patients showed positive SPT. Patients from the Inland region group were significantly more frequently sensitized to pollens than that from Coastal region group. This is probably related to the higher pollen counts found in the Inland region (SPAIC/Schering-Plough/CIPA, 1999), which may cause higher levels of allergic sensitization in the people exposed (Jarvis and Burney, 1998; Taylor et al., 2007).

The sample was homogenous for age and gender, considering the sub-groups of patients sensitized to pollens.

Despite the greater number of patients sensitized to pollens in group A, the magnitude of the elicited wheals is not greater compared with that of group B. Grass pollen extract elicited the largest SPT average wheal diameter in both groups.

The prevalence of sensitization to profilin in the whole sample was $11.62 \%$. Sensitization to profilin was $21.0 \%$ of all pollen sensitized individuals. This percentage is similar to that observed by Valenta et al. (1992) in their first report of profilin as a plant panallergen (20\%) and by Pauli et al. (1996) using rBetv2 for SPT (19.6\%). However Asero et al. (2008) found a higher proportion of sensitization to date palm profilin (30\%) in patients sensitized to pollens. In our study, sensitization to profilin in pollen sensitized patients from the Coastal region (12.5\%) compared with that from the Inland region $(22.2 \%)$ was even lower. These differences might be due to geographical factors.

We found that sensitization to profilin was associated with pollen sensitization as expected. However, 4 patients were sensitized to profilin without sensitization to the pollens tested. This was a bizarre finding. One can wonder if those were false positives or the patients could be sensitized to other pollens not tested in this study. However, we could confirm the results of SPT in one patient (tested negative except for profilin), by repeating the study 11 months after the first evaluation.
Almost all the patients sensitized to profilin lived in the Inland region where the sensitization to pollens is more frequent.

$38.7 \%$ of patients were sensitized to at least half of the pollens tested and $78.5 \%$ were sensitized to at least two pollens.

Most of the patients sensitized to grasses were also sensitized to other pollens (65.1\%) whereas only $7.5 \%$ of patients were mono-sensitized to grasses.

All the 39 patients sensitized to profilins and pollens, were sensitized to at least two pollens and 31 of them were sensitized to at least half of the pollens tested. Mari (2001) has shown, at the molecular level that $55 \%$ of patients with multiple pollen sensitizations had IgE to rBet v 2, the recombinant profilin of Betula verrucosa.

In our patients, the diagnosis was made only by SPT, but we could find that $43 \%$ of patients that were sensitized to more than five pollens were also sensitized to profilin. This slightly lower percentage might be due to differences in the fine specificity of IgE directed to variable epitopes of profilin (Radauer et al., 2006) in our population. This might lead to deficient recognition of profilin from other pollens, compared with patients from other countries.

When we considered the percentage of patients sensitized to more than one pollen, the percentage of sensitization to profilin decreased to $26.7 \%$. These findings agree with the current understanding of profilin as a plant panallergen (Valenta et al., 1992; Radauer et al., 2006; Ebner et al., 1995).

The higher average wheal diameter results of SPT to grasses lead us to explore if sensitization to grasses was negatively related to sensitization to profilin. We could find that mono-sensitization to grasses was not associated with sensitization to profilin, as expected.

A positive association between sensitization to profilin and male gender was found. A possible explanation for this is that a gene or genes responsible for a predisposition to sensitization to profilin can better express their phenotype in males.

From the 43 patients that showed to be sensitized to profilin, only 4 patients had oral allergy syndrome to fruit ingestion namely melon, a clinical manifestation classically described to be associated with sensitization to profilin (Wensing et al., 2002; Asero et al., 2003). As Wensing et al. (2002) showed, in analogy to IgE to carbohydrate determinants, cross-reactive IgE against food profilins have no or very limited clinical relevance. Recently Asero et al. (2008) found that $57 \%$ of patients sensitized to profilin had food allergy. Differences between these studies might be due to different patterns of sensitization in the study populations.

The study of sensitization to profilin is of crucial importance for diagnosis in patients with multiple pollen sensitization (Valenta et al., 1992; Mari, 2001). The diagnosis based on serologic specific IgE determination is presently impossible in normal clinical settings. The use of a profilin extract for SPT can surpass this impracticality.

\section{Conclusion}

We can conclude that SPT with profilin, particularly in the Inland region, might help to differentiate between crossreactivity phenomena and true sensitization to pollens. 
If SPT to profilin is negative, there might be a true sensitization to the different pollens or cross-reactivity by sensitization to other pan-allergen. If the SPT to profilin is positive in a patient poly-sensitized to pollens it is advisable to account the relevant pollens according to medical history. Therefore, the results may support the choice for a specific immunotherapy option as well as to improve the extract selection for treatment.

\section{R E F E R E N C E S}

Aalberse RC, van Ree R. Crossreactive carbohydrate determinants. Clin Rev Allergy Immunol 1997;15:375-87.

Asero R, Mistrello G, Roncarolo D, Amato S, Zanoni D, Barocci F, et al. Detection of clinical markers of sensitization to profilin in patients allergic to plant-derived foods. J Allergy Clin Immunol 2003;112:427-32.

Asero R, Monsalvew R, Barberw D. Profilin sensitization detected in the office by skin prick test: a study of prevalence and clinical relevance of profilin as a plant food allergen. Clin Exp Allergy 2008;38:1033-7.

Asturias JA, Ibarrola I, Fernandez J, Arilla MC, Gonzalez-Rioja R, Martinez A. Pho d 2, a major allergen from date palm pollen, is a profilin: cloning, sequencing, and immunoglobulin $\mathrm{E}$ cross-reactivity with other profilins. Clin Exp Allergy 2005;35:374-81.

Beggs PJ. Impacts of climate change on aeroallergens: past and future. Clin Exp Allergy 2004;34:1507-13.

Bousquet PJ, Chatzi L, Jarvis D, Burney P. Assessing skin prick tests reliability in ECRHS-I. Allergy 2008;63:341-6 Electronic publication 2007 Dec 7.

Brand PL, Kerstjens HA, Jansen HM, Kauffman HF, de-Monchy JG. Interpretation of skin tests to house dust mite and relationship to other allergy parameters in patients with asthma and chronic obstructive pulmonary disease. The Dutch CNSLD Study Group. J Allergy Clin Immunol 1993;91:560-70.

D'Amato G, Liccardi G, Frenguelli G. Thunderstorm-asthma and pollen allergy. Allergy 2007a;62:11-6.

D'Amato G, Cecchi L, Bonini S, Nunes C, Annesi-Maesano I, Behrendt $\mathrm{H}$, et al. Allergenic pollen and pollen allergy in Europe. Allergy 2007b;62:976-90.

Dreborg S. Skin tests used in type I allergy testing position paper. Sub-committee on skin tests of the European Academy of Allergology and Clinical Immunology. Allergy 1989;44 (Suppl. 10):1-59.

Ebner C, Hirschwehr R, Bauer L, Breiteneder H, Valenta R, Ebner H, et al. Identification of allergens in fruits and vegetables: IgE cross-reactivities with the important birch pollen allergens Bet v 1 and Bet v 2 (birch profilin). J Allergy Clin Immunol 1995;95:962-9.

Egger M, Mutschlechner S, Wopfner N, Gadermaier G, Briza P, Ferreira F. Pollen-food syndromes associated with weed pollinosis: an update from the molecular point of view. Allergy 2006;61:461-76.

Elfman L, Svensson M, Lidholm J, Pauli G, Valenta R. Different profiles in specific IgE to rBet $\mathrm{v} 1$ and $\mathrm{rBet} \mathrm{v} 2$ in patients allergic to birch pollen from six countries. Int Arch Allergy Immunol 1997;113:249-51.

Gilmour MI, Jaakkola MS, London SJ, Nel AE, Rogers CA. How exposure to environmental tobacco smoke, outdoor air pollutants and increased pollen burdens influences the incidence of asthma. Environ Health Perspect 2006;114:627-33.

Instituto de Meteorologia. Portugal. Perfil Climático - Portugal Continental; Mars, 2008. clim_ac_00_00www.meteo.pt, available at: http://www.meteo.pt.
Jarvis D, Burney P. ABC of allergies. The epidemiology of allergic disease. BMJ 1998;21(316):607-10.

Kwaasi AAA, Harfi HA, Parhar RS, Saleh S, Collison KS, Panzani RC, et al. Cross-reactivities between date palm (Phoenix dactylifera L.) polypeptides and foods implicated in the oral allergy syndrome. Allergy 2002;57:508-18.

Loureiro G, Rabaça MA, Blanco B, Andrade S, Chieira C, Pereira C. Urban versus rural environment-any differences in aeroallergens sensitization in an allergic population of Cova da Beira, Portugal? Eur Ann Allergy Clin Immunol 2005;37:187-93.

Mari A. Multiple pollen sensitization: a molecular approach to the diagnosis. Int Arch Allergy Immunol 2001;125:57-65.

Mari A, Iacovacci P, Afferni C, Barletta B, Tinghino R, Di Felice G, et al. Specific IgE to cross-reactive carbohydrate determinants strongly affect the in vitro diagnosis of allergic diseases. J Allergy Clin Immunol 1999;103:1005-11.

Ortolani C, Ispano M, Pastorello E, Bigi A, Ansaloni R. The oral allergy syndrome. Ann Allergy 1988;61:47-52.

Pauli G, Oster JP, Deviller P, Heiss S, Bessot JC, Susani M, et al. Skin testing with recombinant allergens $r$ Bet $\mathrm{v} 1$ and birch profilin, rBet v 2: diagnostic value for birch pollen and associated allergies. J Allergy Clin Immunol 1996;97:1100-9.

Pereira C, Valero A, Loureiro C, Dávila I, Martinez-Cócera C, Murio $\mathrm{C}$, et al. Iberian study of aeroallergens sensitisation in allergic rhinitis. Eur Ann Allergy Clin Immunol 2006;38:186-94.

Radauer C, Willerroider M, Fuchs H, Hoffmann-Sommergruber K, Thalhamer J, Ferreira F, et al. Cross-reactive and species-specific immunoglobulin E epitopes of plant profilins: an experimental and structure-based analysis. Clin Exp Allergy 2006;36:920-9.

SPAIC/Schering-Plough/CIPA. In: SPAIC/Schering- Plough/CIPA, editor. Mapa polínico em Portugal; 1999.

Taylor PE, Jacobson KW, House JM, Glovsky MM. Links between pollen, atopy and the asthma epidemic. Int Arch Allergy Immunol 2007;144:162-70.

Thorn KS, Christensen HE, Shigeta R, Huddler D, Shalaby L, Lindberg $\mathrm{U}$, et al. The crystal structure of a major allergen from plants. Structure 1997;5:19-32.

Valenta R, Duchene M, Pettenburger K, Sillaber C, Valent P, Bettelheim $P$, et al. Identification of profilin as a novel pollen allergen; IgE autoreactivity in sensitised individuals. Science 1991;253:557-60.

Valenta R, Duchene M, Ebner C, Valent P, Sillaber C, Deviller P, et al. Profilins constitute a novel family of functional plant pan-allergens. J Exp Med 1992;175:377-85.

Valenta R, Hayek B, Seiberler S, Bugajska-Schretter A, Niederberger V, Twardosz A, et al. Calcium-binding allergens: from plants to man. Int Arch Allergy Immunol 1998;117:160-6.

van der Veen MJ, van Ree R, Aalberse RC, Akkerdaas J, Koppelman $\mathrm{SJ}$, Jansen HM, et al. Poor biologic activity of cross-reactive IgE directed to carbohydrate determinants of glycoproteins. J Allergy Clin Immunol 1997;100:327-34.

van Ree R, van Leeuwen WA, Akkerdaas H, Aalberse RC. How far can we simplify in- vitro diagnostics for Fagales tree pollen allergy? A study with three whole pollen extracts and purified natural and recombinant allergens. Clin Exp Allergy 1999;29:848-55.

Wensing M, Akkerdaas J, van Leeuwen WA, Stapel SO, Bruijnzeel-Koomen CA, Aalberse RC, et al. IgE to Bet v 1 and profilin: cross-reactivity patterns and clinical relevance. J Allergy Clin Immunol 2002;110:435-42.

Witke W. The role of profilin complexes in cell motility and other cellular processes. Trends Cell Biol. 2004;14:461-9.

Witteman AM, Stapel SO, Perdok GJ, Sjamsoedin DHS, Jansen HM, Aalberse RC, et al. The relationship between RAST and skin test results in patients with asthma or rhinitis: a quantitative study with purified major allergens. J Allergy Clin Immunol 1996;97:16-25. 